\title{
Qualitative characterization of a transesterification product of coconut oil by FIA-APCI-MS
}

\author{
M. Cortese ${ }^{1}$, M. Ricciutelli ${ }^{1}$, R. Censi and P. Di Martino \\ School of Pharmacy, University of Camerino, Via S. Agostino 1, 62032 Camerino, Italy
}

Received 30 September 2014, Accepted 16 January 2015

Keywords: chemical analysis, MASS spectroscopy, polymers/surfactants

\begin{abstract}
Synopsis
OBJECTIVES: The purpose of this work was the qualitative characterization of a recently transesterification product obtained from the coconut oil in the presence of polyglycerol- 6 to produce a new PEG-free secondary surfactant. The purpose of a secondary surfactant is to reduce the harshness of a skin cleanser.

METHODS: The transesterification product was qualitatively characterized in our laboratory by flow injection analysis-atmospheric pressure chemical ionization-mass spectrometry (FIA-APCI-MS) The mass spectrum of the transesterification product was compared to those of the starting materials (polyglycerol and coconut oil).

RESULTS: The analyses highlighted the disappearance of the starting oil peaks and the appearance of new peaks assignable to the reaction products, mainly corresponding to diesters of polyglycerol. Additionally, peaks of unreacted polyglycerol are present as well as peaks of cyclization products derived from the polyglycerol starting material.

CONCLUSIONS: The development of this fast and easy analytical method, requesting only few minutes to be performed, represents a very useful tool for the characterization of transesterification products during the quality control of batches under production.
\end{abstract}

\section{Résumé}

OBJECTIFS: Le but de ce travail était la caractérisation qualitative d'un produit de transestérification récemment obtenu à partir de l'huile de noix de coco en présence de polyglycérol-6 pour produire un nouveau tensioactif secondaire sans PEG, ce dernier généralement ajouté pour réduire l'agressivité d'un nettoyant pour la peau. MÉTHODES: Le produit de transestérification a été qualitativement caractérisé dans notre laboratoire par Analyse du Débit d'injection - par Ionisation chimique à Pression atmosphérique - par Spectrométrie de masse (FIA-APCI-MS). Le spectre de masse du produit de transestérification a été comparé à ceux des matériaux de départ (de polyglycérol et d'huile de noix de coco).

RÉSULTATS: Les analyses ont mis en évidence la disparition des pics d'huile de départ et l'apparition de nouveaux pics attribuables à des produits de réaction, correspondant principalement à des diesters de polyglycérol. De plus, les pics de polyglycérol non réagi sont présents ainsi que des pics de produits de cyclisation provenant de la matière de départ de polyglycérol.

Correspondence: Piera Di Martino, School of Pharmacy, University of Camerino, Via S. Agostino 1, 62032 Camerino, Italy. Tel.: +390737 402215; fax: +390737637345; e-mail: piera.dimartino@unicam.it

${ }^{1}$ These authors are contributed equally to this work.
CONCLUSIONS: Le développement de cette méthode d'analyse rapide et facile représente un outil très utile pour la caractérisation des produits de transestérification pendant le contrôle de la qualité des lots en production.

\section{Introduction}

In the cosmetic field, the development of new green materials, particularly surfactants, is emerging as an urgent need for the production of environmentally responsible cosmetic products. With increased strain on petroleum resources and consumer awareness about the environment, the market demand for sustainable products has never been higher.

Sustainability in cosmetics is thus becoming one of the pressing issues in the development of new materials and products. 'Sustainable Consumption and Production and Sustainable Industrial Policy (SCP/SIP) Action Plan' [1] encourages innovation in terms of sustainability.

Thus, in the last years, the cosmetic industry acknowledged the importance of a sustainable approach for the production of their ingredients [2]. The development of new green materials translates into the application of new green production processes (e.g. avoiding organic solvents); the absence of non-biodegradable materials, such as polyethylene glycols (products PEG-free); low impact on the environment; and energy savings.

Secondary surfactants are milder surfactants added to the primary ones to reduce the harshness and improve the foaminess of a skin cleanser. Among the secondary surfactants, amphoteric, nonionic and few anionic are used.

Recently, several secondary surfactants were developed and produced through a transesterification process from vegetable oils [3, $4]$, with very low impact on the environment. The transesterification [5] refers to the process of exchanging the organic group R" of an ester with the organic group $\mathrm{R}^{\prime}$ of an alcohol, as shown in Fig. 1. The transesterification may confer new interesting properties to the vegetable oils, such as the capacity to disperse in water, which justifies their use as surfactants. In addition, the neutral character of the molecule makes these products very mild and appropriate secondary surfactants for sensitive skin formulations.

$\mathrm{R}^{\prime} \mathrm{OH}+$

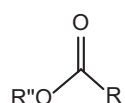<smiles>C1CC2CC1C2</smiles><smiles>[R6]C(=O)P</smiles>

Figure 1 General transesterification reaction. 
The objectives of this study were the qualitative characterization of a transesterification product obtained from the reaction between the coconut oil and the polyglycerol- 6 by flow injection analysis-atmospheric pressure chemical ionization-mass spectrometry (FIA-APCI-MS) and the development of a new, easy and fast method for the characterization of the transesterification products, to be applied during the quality control of the batches under production.

In Fig. 2, a general transesterification reaction is given, were a general polyglycerol reacts with a triglyceride. Theoretically, and according to the number and the position of reacting hydroxyl groups into the polyglycerol molecule, the number of possible reaction product is high. In Fig. 2, as an example, monoesterified and diesterified polyglycerols are reported. At present, a transesterification product is commercialized as soft cleanser for sensitive skin (INCI: coconut oil polyglycerol-6 esters).

Due to the complexity of the mixture under characterization, the APCI-MS has been chosen as the best method for the qualitative characterization, because it has been previously applied for the characterization of natural compounds, demonstrating effectiveness in the characterization of very complex compositions. For example, the APCI was selected as the best ionization source to be used in MS for the characterization of triacylglycerols and diacylglycerols in 16 plant oil samples [6].

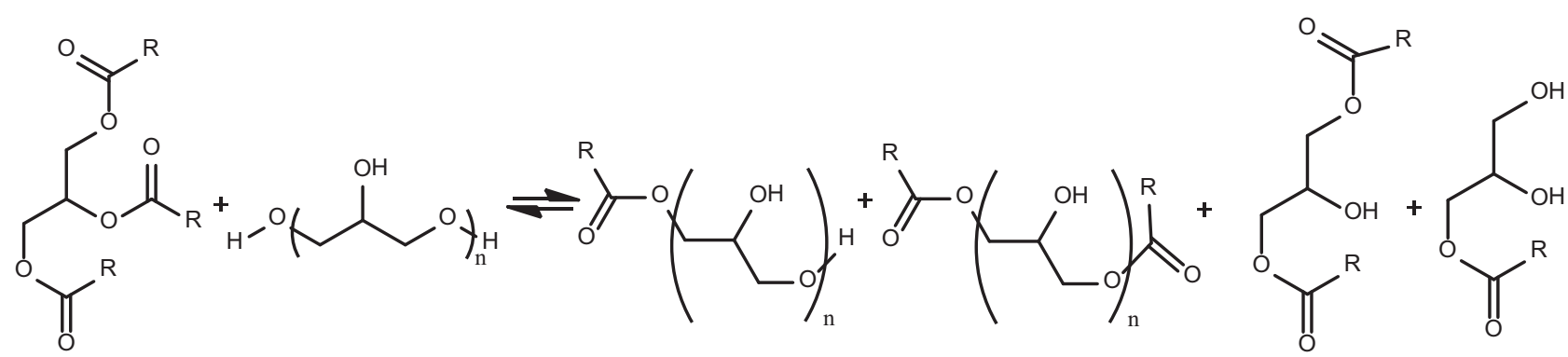

(a)

(b)

Figure 2 Transesterification reaction between a triglyceryde and a polyglycerol; the reported products are monoesterified polyglycerol (a), and diesterified polyglycerol (b), taken as examples of the theoretically large number of reaction products ( $\mathrm{R}=$ alkyl chain of fatty acids; $\mathrm{n}=$ from 1 to 7 ).<smiles>[R]C(=O)OCC([O-])OC([R])=O</smiles>

Figure 3 Possible fragmentation of a triglyceride in APCI. The three possible pathway a, b, c of the ionization process of the same triglyceride in APCI source are shown. The fragmentation involves the loss of one of the three fatty acids $\left(R_{1}, R_{2}, R_{3}=\right.$ alkyl chain of fatty acid). 
Table I Fatty acid composition of coconut oil starting material as determined by the supplier by gas chromatography. The fatty acid composition complies with Codex standard [8]

\begin{tabular}{llll}
\hline Fatty acids & & & Percentage (\%) \\
\hline C & C8:0 & Caprylic & 8.0 \\
D & C10:0 & Capric & 5.1 \\
La & C12:0 & Lauric & 45.1 \\
M & C14:0 & Myristic & 19.1 \\
P & C16:0 & Palmitic & 10.0 \\
S & C18:0 & Stearic & 2.0 \\
O & C18:1 & Oleic & 8.0 \\
L & C18:2 & Linoleic & 0.5 \\
\hline
\end{tabular}

In addition, the flow injection analysis (FIA) was selected because fast and easy method appropriate for the routinely quality control. The FIA was applied to directly inject the samples into the mass spectrometer without a preliminary chromatographic separation.

\section{Materials and methods}

\section{Chemicals}

The coconut oil (CO), the polyglycerol-6 (PG6) and the product of transesterification (TP) were kindly supplied by Res Pharma (Milan, Italy). HPLC-MS grade solvents (acetonitrile, acetone, isopropanol) were all provided by Sigma-Aldrich (Stenheim, Germany).
Table II Composition of pure vegetable polyglycerol- 6 as determined by the supplier and used for the transesterification reaction with the coconut oil

\begin{tabular}{llc}
\hline Composition & & Percentage (\%) \\
& & \\
\hline & & $<1$ \\
Gly & Glycerol & 8.05 \\
PG2 & Total diglycerol & 25.57 \\
PG3 & Total triglycerol & 21.78 \\
PG4 & Total tetraglycerol & 14.50 \\
PG5 & Pentaglycerol & 9.03 \\
PG6 & Hexaglycerol & 6.27 \\
PG7 & Heptaglycerol & 4.38 \\
PG8 & Octaglycerol & 3.09 \\
PG9 & Nonaglycerol & $<0.5$ \\
PG10 and highers & Decaglycerol and highers & \\
& & \\
\hline
\end{tabular}

\section{Methods of analysis}

Analyses were performed with a single quadrupole mass spectrometer (Series 1100/MSD; Agilent Technologies, Santa Clara, CA, USA). Preliminary two different ionization sources were used: the electrospray ionization (ESI) and the atmospheric pressure chemical ionization (APCI). Samples were dissolved in a mixture of acetonitrile/acetone/isopropanol $(1: 1: 1)$, filtered through a $0.45-\mu \mathrm{m}$ PTFE filter (Sartorius, Goettingen, Germany) and injected at a concentration of $10 \mathrm{mg} \mathrm{mL}^{-1}$ at an injection volume of $2 \mu \mathrm{L}$. The eluent was acetonitrile-acetone $36: 64 \mathrm{~V} / \mathrm{V}$ [7]. The scanning range was $50-1500 \mathrm{~m} / \mathrm{z}$ in the positive mode. The drying gas flow rate was set to $10 \mathrm{~L} \mathrm{~min}^{-1}$; the nebulizer pressure was $30 \mathrm{psi}$; the drying gas temperature was $350^{\circ} \mathrm{C}$; and the capillary voltage was $4000 \mathrm{~V}$ for both sources. Specifically, for APCI source, the vaporizer

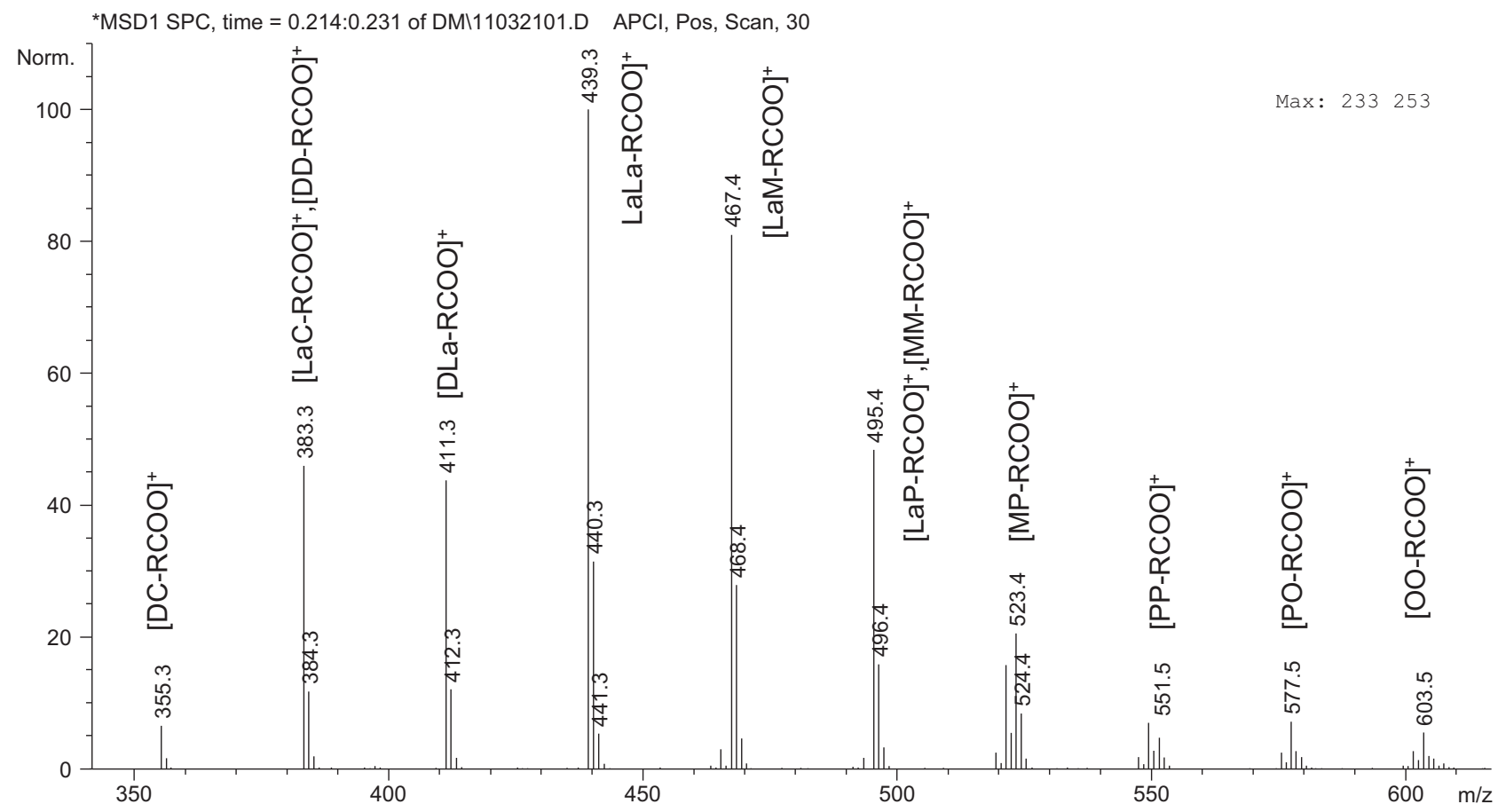

Figure 4 Mass spectrum of coconut oil. The most probable fragment is associated to every signal according to the literature [9, 10]. 


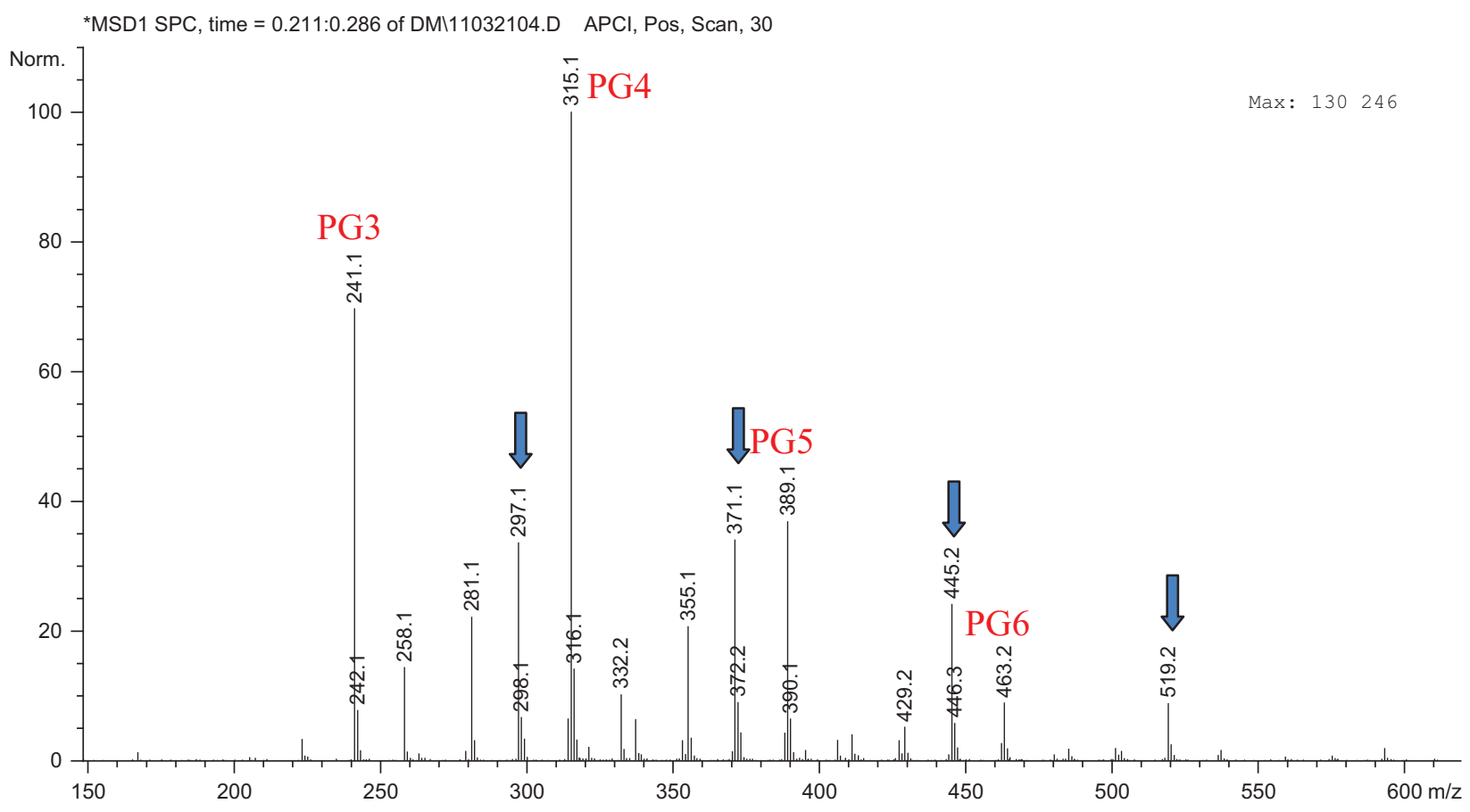

Figure 5 Mass spectrum of the pure vegetable polyglycerol-6 used in the present study. In spite of the name, the most abundant species are PG3, PG4, and PG5, in accordance with the product certificate of analysis reported in Table I. The symbols PG3, PG4, PG5, and PG6 are indicated in correspondence to the relative fragment. The peaks indicated by an arrow correspond to $\mathrm{m} / \mathrm{z}$ value compatible with the cyclic specie of the subsequent polyglycerol.<smiles>OCC(O)COCC(O)CO</smiles>

(a)<smiles>OCC(O)COC(CO)CO</smiles>

(b)<smiles>OCC(CO)OC(CO)CO</smiles>

(c)<smiles>OCC1COC(CO)CO1</smiles>

(d)<smiles>OCC1COCC(CO)O1</smiles>

(e)

Figure 6 List of all the possible linear (a, b, c) and cyclic (d, e) forms of diglycerol, the smallest polyglycerol. For the higher homologues PG ${ }_{n}$, the number of the possible forms increases proportionally to the $n$ value.

temperature was enabled and set to $325^{\circ} \mathrm{C}$, whereas the corona current was $4 \mu \mathrm{A}$.

\section{Results and discussion}

At the beginning of this study, two ionization sources (the electrospray ionization - ESI and the atmospheric pressure chemical ionization - APCI) were preliminary applied.
Electrospray ionization (ESI) and atmospheric pressure chemical ionization (APCI) are the most used soft ionization sources (normally there is not fragmentation) to coupling liquid chromatography to mass spectrometry.

The ESI is more suitable for very polar molecules that can have also large molecular weight (until $1000000 \mathrm{Da}$ ), whereas the APCI is commonly used to analyse smaller, thermally stable polar and non-polar compounds. 


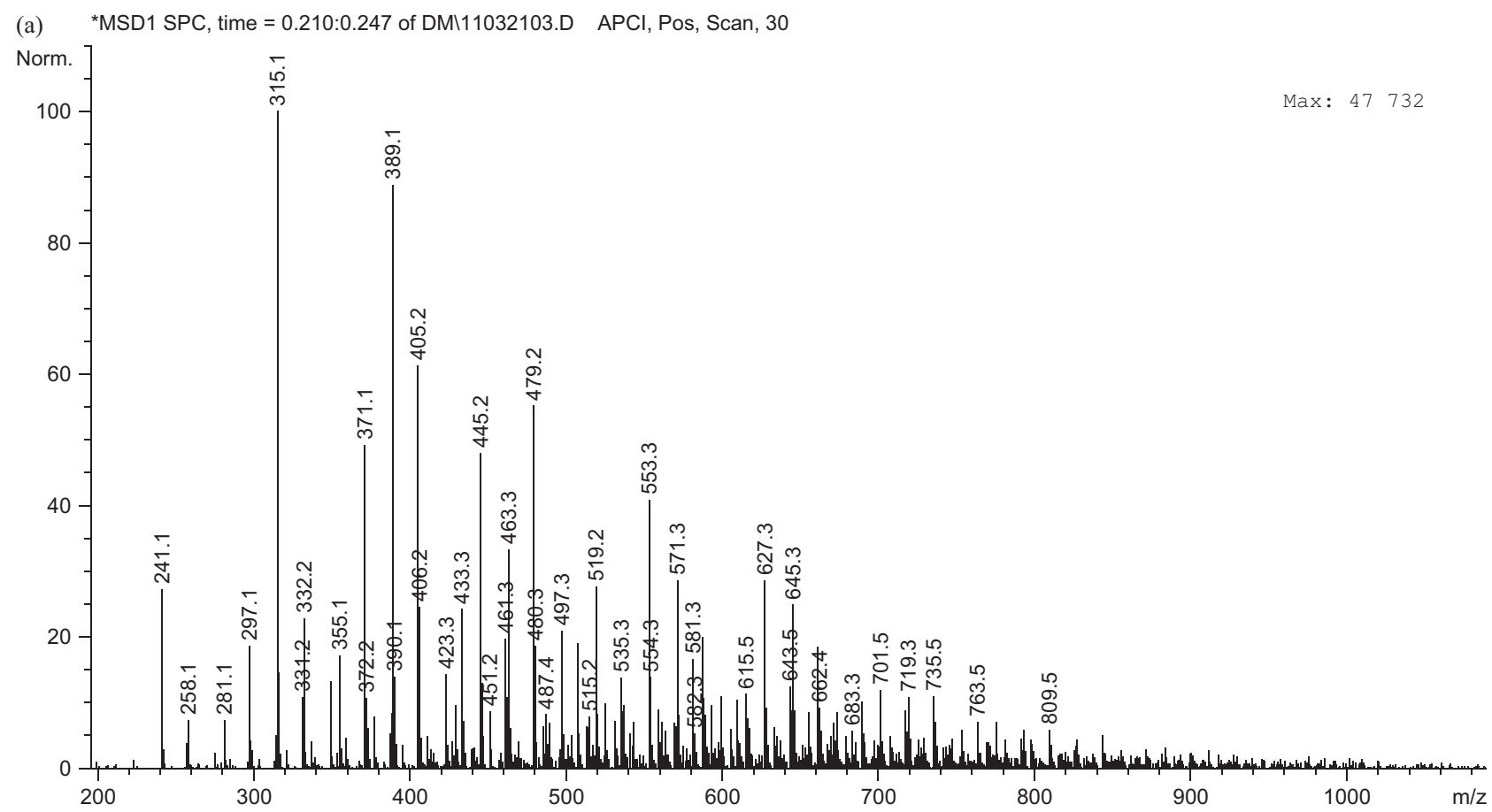

(b) *MSD1 SPC, time $=0.210: 0.247$ of DMl11032103.D APCI, Pos, Scan, 30

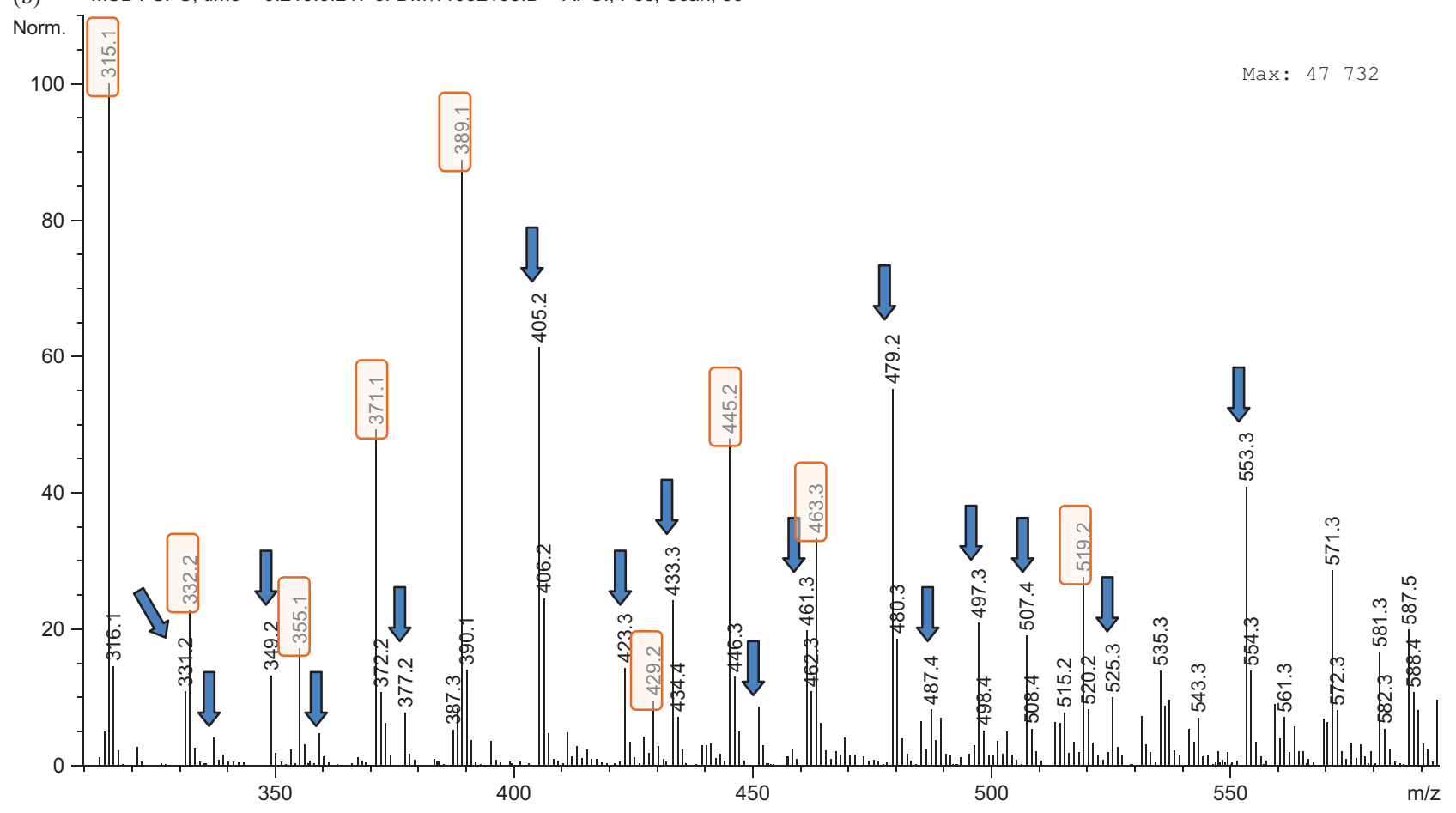

Figure 7 (a) Mass spectrum of the transesterificated coconut oil with the PG6. (b) Range 300-600 m/z of the same mass spectrum. Arrows indicate the diester formed during the transesterification, while the squared numbers correspond to the unreacted PG6. 
They may be coupled to the flow injection analysis (FIA) that allows the introduction of the sample into the apparatus without a previous separation.

Triester and transesterified polyglycerols do not show very polar characteristics, leading to a very low ionization efficiency with ESI source. For this reason, only the APCI was considered for the development of the method of analysis.

In Fig. 3, the fragmentation reaction is reported, showing the three products that can be obtained in APCI source from the same triglyceride, depending on which fatty acid is lost during the ionization process.

The composition of the coconut oil starting material, as determined by the supplier by gas chromatography, is reported in Table I. The fatty acid composition complies with the Codex standard [8]. Nearly $89 \%$ is represented by saturated fatty acids, the $45 \%$ being the C12. In Fig. 4, the MS spectrum of coconut oil determined in our experiments is reported. Each peak corresponded to the triester that fragmented under the applied experimental conditions by losing one of the three fatty acids, according to the literature [6].

The most probable fragment is associated with every signal according to the literature $[9,10]$.

To better assign any signal, authors evaluated all the combinations for every molecular weight; finally, the assignment was attributed taking into account the combinations actually present in the coconut oil and reported into the literature. For example, for the molecular weight of 439 Dalton, there were three possible combinations $\left([\mathrm{CP}-\mathrm{RCOO}]^{+},[\mathrm{DM}-\mathrm{RCOO}]^{+}\right.$and $\left.[\mathrm{LaLa}-\mathrm{RCOO}]^{+}\right)$, but only one fragment was selected corresponding to the positive ion [LaLa$\mathrm{RCOO}^{+}$based on results previously reported into the literature. In fact, only this last fragment is compatible with the list of triester identified in coconut oil $[9,10]$.

In Table II, the composition of pure vegetable polyglycerol- 6 as determined by the supplier and used for the transesterification reaction is given, where, in spite of the commercial denomination (polyglycerol-6), the most abundant species are PG3, PG4 and PG5, as also confirmed by our analyses (Fig. 5). The PG6 spectrum (Fig. 5) determined in our experiments shows that main peaks corresponded to the formation of the pseudomolecular ion $[\mathrm{M}+\mathrm{H}]^{+}$ for all polyglycerols. The most abundant oligomers are PG3, PG4 and PG5, according to the composition described in Table II. The analysis of the spectrum of the polyglycerol showed the presence of $\mathrm{m} / \mathrm{z}$ values compatible with the pseudomolecular ion of the cyclic PG corresponding to each polyglycerol, which has a $\mathrm{m} / \mathrm{z}$ value comparable to the linear PG without one water molecule $\left[\mathrm{M}_{\mathrm{PGcyclic}}+\mathrm{H}\right]^{+}$(Fig. 5). Those peaks are indicated by an arrow in Fig. 5. A list of all the possible linear and cyclic forms of diglycerol, the smallest polyglycerol, is given in Fig. 6. For the higher homologues $\mathrm{PG}_{n}$, the number of the possible forms increases with the $n$ value.

Finally, the coconut oil transesterified with the polyglycerol was analysed (Fig. 7). By comparing this last spectrum with the previous ones (Fig. 5), it is possible to observe the appearance of new peaks assignable to the reaction products (refer to the arrow in Fig. 7), peaks related to the unreacted polyglycerol (squared numbers in Fig. 7) and the disappearance of the peaks of the starting oil. These observations proved that the coconut oil reacted quantitatively. With the aim to identify the transesterification products, a database was created deriving from the combination between the molecular weights of polyglycerol components and fatty acids present in coconut oil.
Table III Identification of diester residue by comparison of calculated and experimental $\mathrm{m} / \mathrm{z}$ values

\begin{tabular}{|c|c|c|}
\hline $\begin{array}{l}\text { Diester residue } \\
\text { ion [Diester }-\mathrm{RCOO}^{+}\end{array}$ & $\begin{array}{l}\text { Calculated } \\
\mathrm{m} / \mathrm{z} \text { value }\end{array}$ & $\begin{array}{l}\text { Experimental } \\
\mathrm{m} / \mathrm{z} \text { value }\end{array}$ \\
\hline Gly-C12:0 & 257.22 & 257.1 \\
\hline PG2-C8:0 & 275.19 & 275.3 \\
\hline PG2-C10:0 & 303.22 & 303.0 \\
\hline PG2-C12:0 & 331.25 & 331.2 \\
\hline Gly-C18:2 & 337.28 & 337.2 \\
\hline PG3-C8:0 & 349.23 & 349.2 \\
\hline PG2-C14:0 & 359.28 & 359.2 \\
\hline PG3-C10:0 & 377.26 & 377.2 \\
\hline PG3-C12:0 & 405.29 & 405.2 \\
\hline PG4-C8:0 & 423.27 & 423.3 \\
\hline PG3-C14:0 & 433.32 & 433.3 \\
\hline PG4-C10:0 & 451.30 & 451.2 \\
\hline PG3-C16:0 & 461.35 & 461.3 \\
\hline PG4-C12:0 & 479.33 & 479.2 \\
\hline PG3-C18:2 & 485.35 & 485.4 \\
\hline PG3-C18:1 & 487.37 & 487.4 \\
\hline PG3-C18:0 & 489.38 & 489.4 \\
\hline PG5-C8:0 & 497.30 & 497.3 \\
\hline PG4-C14:0 & 507.36 & 507.4 \\
\hline PG5-C10:0 & 525.33 & 525.3 \\
\hline PG4-C16:0 & 535.39 & 535.3 \\
\hline PG5-C12:0 & 553.36 & 553.3 \\
\hline PG4-C18:2 & 559.39 & 559.3 \\
\hline PG4-C18:1 & 561.41 & 561.3 \\
\hline PG4-C18:0 & 563.42 & 563.3 \\
\hline PG6-C8:0 & 571.33 & 571.3 \\
\hline PG5-C14:0 & 581.39 & 581.3 \\
\hline PG6-C10:0 & 599.36 & 599.3 \\
\hline PG5-C16:0 & 609.42 & 609.3 \\
\hline PG6-C12:0 & 627.39 & 627.3 \\
\hline PG5-C18:0 & 637.45 & 633.4 \\
\hline PG5-C18:1 & 635.44 & 635.4 \\
\hline PG5-C18:2 & 633.42 & 637.4 \\
\hline PG7-C8:0 & 645.36 & 645.3 \\
\hline PG6-C14:0 & 655.42 & 655.3 \\
\hline PG7-C10:0 & 673.39 & 673.3 \\
\hline PG6-C16:0 & 683.45 & 683.3 \\
\hline PG7-C12:0 & 701.42 & 701.5 \\
\hline PG6-C18:2 & 707.45 & 707.5 \\
\hline PG6-C18:1 & 709.47 & 709.5 \\
\hline PG6-C18:0 & 711.48 & 711.5 \\
\hline PG8-C8:0 & 719.42 & 719.3 \\
\hline PG9-C12:0 & 775.45 & 775.5 \\
\hline
\end{tabular}

For diester species, the formula for the identification of their fragment in mass spectrum is

$$
M W_{\mathrm{FA}}+M W_{\text {Polyglycerol }}-\left[\mathrm{H}_{2} \mathrm{O}\right]-17
$$

whereas for triglyceride species, the formula is

$$
M W_{\mathrm{FA} 1}+M W_{\mathrm{FA} 2}+M W_{\text {Polyglycerol }}-2\left[\mathrm{H}_{2} \mathrm{O}\right]-17
$$

where $M W_{\mathrm{FA}}, M W_{\text {Polyglycerol }}$ and $M W_{\mathrm{H} 2 \mathrm{O}}$ refer to the molecular weight of fatty acids, polyglycerol and water, respectively.

According to the mechanism of fragmentation occurring in the APCI source of these species, it was possible to identify each ion (Table III). As explained before, in the ionization process, only one fatty acid is lost (Fig. 3), so diesters $\mathrm{m} / \mathrm{z}$ peak correspond to the only one remained fatty acid [diester-RCOO $]^{+}$. The $\mathrm{m} / \mathrm{z}$ values resulted mainly compatible with diesters as the most abundant 
species, even if it was possible to find little amount of products deriving from a single transesterification process. The formation of triesters or more complex species was not observed in the reaction condition. It is necessary to point out that the composition of the transesterification product between an oil and a polyglycerol depends on the reaction conditions (temperature, catalyst, molar ratio of polyglycerol/coconut oil). In this study, the reaction conditions cannot be reported because they are confidential. This interpretation of the mass spectrum lead to the identification of a transesterification product deriving from $\mathrm{C} 12: 0$ with all the PG species, as the main reaction products. This conclusion is in line with the coconut oil composition, where $\mathrm{C} 12: 0$ is the major compound (Table I). This behaviour can be also found for the minor oil components respecting the relative abundance of each fatty acid in the starting material.

A quantitative evaluation of each compound was not possible because there was no information about the ionization efficiency of each class compounds (monoesters, diesters, triesters) due to the lack of standards of each polyglycerol esters.

The qualitative interpretation of the spectra is very complex. To adequately analyse such complex mixtures, it should be necessary to proceed with a chromatographic separation of each fraction to further analyse every component with an appropriate detector [11]. Anyway, the aim of this work was rather the possibility to detect a simple and fast method for the characterization of the transesterification product as quality control method. Actually, this goal was achieved by applying a FIA-APCI-MS method directly to the mixture.

\section{Conclusions}

A complete characterization of a complex mixture deriving from a transesterification reaction, and thus, the analysis of polyglycerol fatty acid esters is highly laborious as demonstrated by De Meulenaer et al. [11].

In the present study, a very complex mixture of components derived from the transesterification reaction of coconut oil with polyglycerol was adequately characterized from a qualitative point of view by FIA-APCI-MS, giving important information about the yield of the reaction and the nature of the obtained products. The analysis of every complex mixture goes on only one minute against the time requested for a chromatographic separation that can take from several minutes to one hour, in general. The developed analytical method may represent a fast and easily applicable method for cosmetic industries during the quality control of the transesterification batches under production.

\section{Acknowledgements}

The authors would like to thank Res Pharma (Milan, Italy) for the financial support to this study.

\section{References}

1. COM (2008) 397 final, Communication from the Commission to the European Parliament, the Council, the European Economic and Social Committee and Committee of the Regions on the Sustainable Consumption and Production and Sustainable Industrial Policy Action Plan, Brussels, 16.7.2008.

2. Sahota, A. Sustainability: How the Cosmetics Industry is Greening Up. ISBN: 978-1-11994554-3. John Wiley \& Sons, West Sussex, UK (2014).

3. Schuchardt, U., Sercheli, R. and Vargas, R.M. Transesterification of vegetable oils: a review. J. Braz. Chem. Soc. 9, 199-210 (1998).

4. Shahla, S., Cheng, N.G. and Yusoff, R. An overview on transesterification of natural oils and fats. Biotechnol. Bioprocess Eng. 15, 891-904 (2010).
5. Riemenschneider, W. and Bolt, H.M. Esters, Organic. Ullmann's Encyclopedia of Industrial Chemistry. Wiley-VCH, Weinheim (2005).

6. Holcapek, M., Jandera, P., Zderadicka, P. and Hruba, L. Characterization of triacylglycerol and diacylglycerol composition of plant oils using high-performance liquid chromatography-atmospheric pressure chemical ionization mass spectrometry. J. Chromatogr. A 1010, 195-215 (2003)

7. Parcerisa, J., Casals, I., Boatella, J., Codony, R. and Rafecas, M. Analysis of olive and hazelnut oil mixtures by high-performance liquid chromatography-atmospheric pressure chemical ionization mass spectrometry of triacylglycerols and gas-liquid chromatography of non-saponifiable compounds (tocopherols and sterols). J. Chromatogr. A 881, 149-158 (2000).
8. Alimentarius, C. Codex standard for named vegetable oils. Codex Stan. 210, 5-13 (2003).

9. Reena, M.B., Reddy, S.R.Y. and Lokesh, B.R. Changes in triglyceride molecular species and thermal properties of blended and interesterified mixtures of coconut oil or palm oil with rice bran oil or sesame oil. Eur. J. Lipid Sci. Technol. 111, 346-357 (2009).

10. Marina, A.M., Che Man, Y.B., Nasimah, S.A.H. and Amin, I. Chemical properties of virgin coconut oil. J. Am. Oil Chem. Soc. 86 301-307 (2009).

11. De Meulenaer, B., Van Royen, G., Vanhoutte, B. and Huyghebaert, A. Combined liquid and gas chromatographic characterisation of polyglycerol fatty acid esters. J. Chromatogr. A 896, 239-251 (2000). 